\title{
AVALIAÇÃO DO DESENVOLVIMENTO VEGETATIVO DAS ESPÉCIES DE GIRASSOL (Helianthus annus) E FEIJÃO-DE- PORCO (Canavalia ensiformis) CULTIVADAS EM SOLO DE PASSIVO AMBIENTAL
}

Evaluation of the vegetative development of species of sunflower (Helianthus annus) and pig bean (Canavalia ensiformis) cultivated in environmental passive soil

Eliane Baptista Barbosa, Daniela Aparecida Baptista Barbosa, Isabela Marega Rigolin Fuzeto, Milena Cristina Ferreira Sanchez

Universidade do Oeste Paulista - UNOESTE, Presidente Prudente, SP. E-mail: ebaptistabarbosa@gmail.com

RESUMO - A disposição adequada dos resíduos sólidos é considerada um desafio a muitos municípios brasileiros que ainda dispõem seus resíduos em aterros controlados e lixões, grandes causadores de passivo ambiental. Sendo o solo um dos componentes ambientais mais afetados por essa prática, o objetivo do presente trabalho é avaliar o desenvolvimento vegetativo do girassol e feijão-de-porco cultivados em solo de passivo ambiental oriundo da destinação inadequada de resíduos sólidos. Foram coletadas amostras de solo de um lixão desativado localizado no Oeste Paulista e uma amostra testemunha, a fim de comparar o desenvolvimento das espécies nos diferentes solos. O estudo foi desenvolvido em casa de vegetação, a partir do Delineamento de Blocos Casualizados, com dezesseis parcelas experimentais, durante 45 dias. Foram avaliados parâmetros de fertilidade do solo e produção de biomassa das espécies. Os resultados foram submetidos à análise de variância e ao teste de comparação de médias Tukey. Constatou-se significativa influência dos resíduos sólidos sobre a disponibilidade de nutrientes do solo, que apresentou teores elevados de macronutrientes e matéria orgânica. A espécie de feijão-de-porco destacou-se pela maior produção de biomassa comparada ao girassol, o que indica a possibilidade de uso dessa espécie na fitorremediação desse solo de passivo ambiental.

Palavras-chave: desenvolvimento vegetativo; passivo ambiental; solo; resíduos sólidos.

ABSTRACT - The proper disposal of solid waste is considered a challenge to many Brazilian municipalities that still dispose of their waste in controlled landfills and dumps, major causes of environmental liabilities. As the soil is one of the environmental components most affected by this practice, the objective of this work is to evaluate the vegetative development of sunflower and jack bean cultivated in soil with environmental liability arising from inadequate disposal of solid waste. Soil samples were collected from a deactivated dump located in the west of São Paulo and a control sample, in order to compare the development of species in different soils. The study was carried out in a greenhouse, from the Design of Randomized Blocks, with sixteen experimental 
plots, during 45 days. Soil fertility parameters and biomass production of the species were evaluated. The results were submitted to analysis of variance and the Tukey mean comparison test. There was a significant influence of solid waste on the availability of nutrients in the soil, which showed high levels of macronutrients and organic matter. The pig bean species stood out for its higher biomass production compared to sunflower, which indicates the possibility of using this species in the phytoremediation of this environmentally passive soil.

Keywords: vegetative development; environmental liability; ground; solid waste.

\section{INTRODUÇÃO}

A disposição inadequada de resíduos sólidos é um problema ainda comum na realidade contemporânea brasileira. Devido a crescente geração de resíduos pela população, a sua disposição final adequada ainda é considerada um desafio aos municípios brasileiros. Representando um dos principais problemas ambientais do país, a disposição desordenada dos resíduos sólidos no meio ambiente pode acarretar na poluição e contaminação dos meios físico e biótico.

Mesmo após a implementação da Lei $n$ o 12.305/2010, que instituiu a Política Nacional de Resíduos Sólidos, e consiste num instrumento essencial na busca de soluções para a problemática ambiental dos resíduos sólidos no Brasil, grande parte dos municípios brasileiros ainda enfrentam dificuldades para realizar a gestão e o gerenciamento de seus resíduos. Segundo a Associação Brasileira de Empresas de Limpeza Pública (Abrelpe, 2019), atualmente 40,5\% dos municípios brasileiros ainda dispõem seus Resíduos Sólidos Urbanos de maneira inadequada.

Em relação a destinação final de resíduos sólidos, existem três formas de disposição: aterro sanitário, aterro controlado e lixão. Sendo a disposição final em aterros sanitários, a única forma considerada como ambientalmente adequada. A disposição de resíduos em aterros controlados e lixões impactam negativamente o meio ambiente, podendo promover a contaminação do solo, do ar e das águas superficiais e subterrâneas. Além de oferecer riscos à saúde pública devido a proliferação de vetores de doenças.

O solo é um dos elementos ambientais mais afetados pelo descarte de resíduos sólidos. Devido a decomposição dos resíduos e produção do chorume, a disposição de resíduos no solo sem a devida proteção pode resultar em elevados níveis de degradação, alterando significativamente as suas características físicas, químicas e biológicas (Marinho et. al, 2019).

Diante disso, considerando o risco de contaminação, se faz necessária a aplicação de técnicas de remediação em áreas de passivo ambiental gerados pela disposição inadequada de resíduos sólidos urbanos. $\mathrm{Na}$ busca por alternativas para despoluir áreas contaminadas por diferentes compostos, procura-se identificar técnicas que apresentem eficiência na descontaminação, simplicidade na execução, menor tempo demandado pelo processo e menor custo (COUTINHO; BARBOSA, 2007).

Dentre as técnicas existentes, a fitorremediação tem se mostrado promissora na remediação de áreas contaminadas. Para a aplicação desta técnica, a espécie vegetal selecionada deve apresentar, entre outras características, um crescimento rápido, elevada produção de biomassa e tolerância à poluição (Lamego e Vidal, 2007). Deste modo, faz-se necessário avaliar o desenvolvimento vegetativo de uma espécie, quando se pretende utilizá-la no processo de fitorremediação, portanto, o presente trabalho tem como objetivo avaliar o desenvolvimento vegetativo das espécies de girassol (Helianthus annuus) e feijão de porco (Canavalia ensiformis) cultivadas em solo de área de passivo ambiental gerado pela disposição inadequada de resíduos sólidos urbanos.

\section{MATERIAL E MÉTODOS}

$O$ experimento foi conduzido em casa de vegetação na Escola Técnica Estadual Prof. Dr. Antônio Eufrásio de Toledo, em Presidente Prudente - SP. Situado na região oeste do Estado de São Paulo, o município localiza-se a $475 \mathrm{~m}$ de 
altitude com as seguintes coordenadas geográficas: Latitude $22^{\circ} 07^{\prime} \mathrm{S}$ e Longitude $51^{\circ} 27^{\prime}$ O. A classificação climática de Presidente Prudente, segundo Köppen-Geiger, é Aw (clima tropical com estação seca de inverno), com temperatura média anual de $24,3^{\circ} \mathrm{C}$ (Barbosa, 2020).

\subsection{Coleta do solo}

As amostras de solo foram coletadas na área de um lixão desativado de um município de pequeno porte, localizado no Oeste Paulista. A coleta foi realizada com o auxílio de uma sonda de amostragem (trado), na profundidade de 0 $30 \mathrm{~cm}$ em 10 pontos divididos aleatoriamente, com base no grau de acessibilidade, ao longo da extensão da área. Foram coletadas também, amostras de solo em um ponto à montante da área do lixão, para constituir o solo testemunha. Todo o volume de solo foi acondicionado em sacos plásticos devidamente identificados.

Posteriormente, as amostras foram peneiradas (peneira aro 55 com 24 fios malha 6) (Figura1), homogeneizadas e acondicionadas em 16 sacos de polietileno de $1 \mathrm{~kg}$ cada (Figura 2), para constituir as parcelas experimentais do Delineamento Experimental.

Figura 1. Peneiramento das amostras de solo.

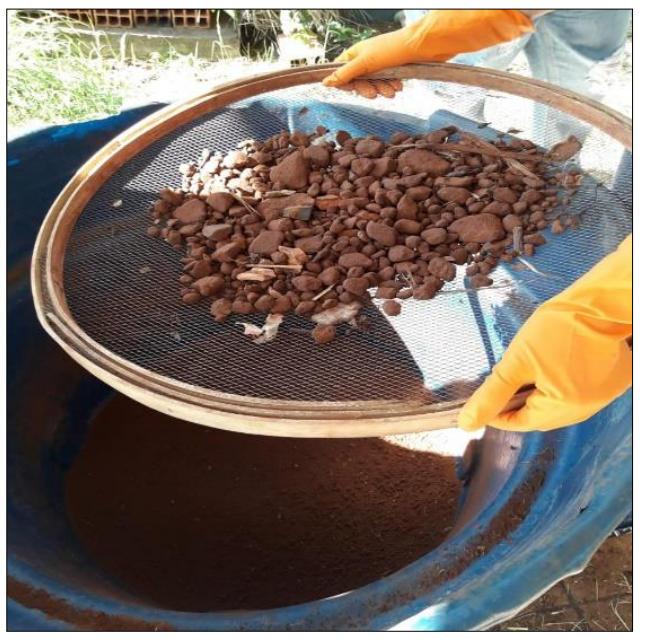

Fonte: Os aOs autores (2020).
Figura 2. Acondicionamento do solo em sacos de polietileno.

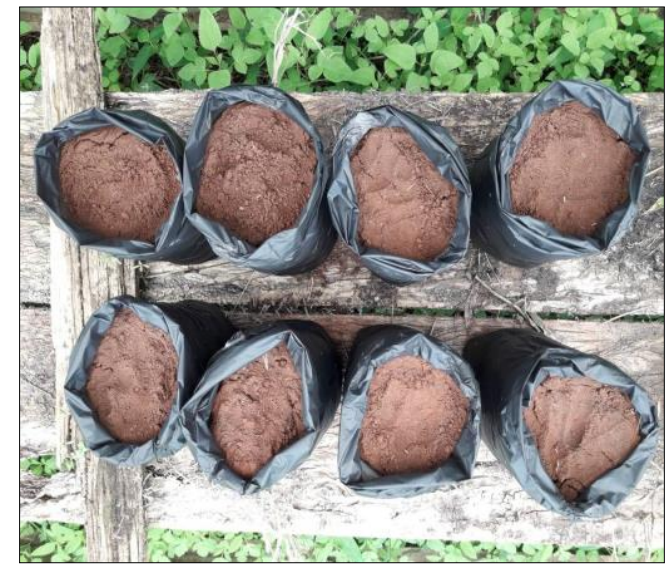

Fonte: Os Os autores (2020).

\subsection{Delineamento Experimental}

$O$ experimento foi instalado seguindo o delineamento estatístico em blocos casualizados (DBC), conforme apresentado na Figura 3, com quatro tratamentos (presença de espécies vegetais) e com quatro repetições (blocos), totalizando dezesseis parcelas experimentais.

Figura 3. Representação do delineamento experimental

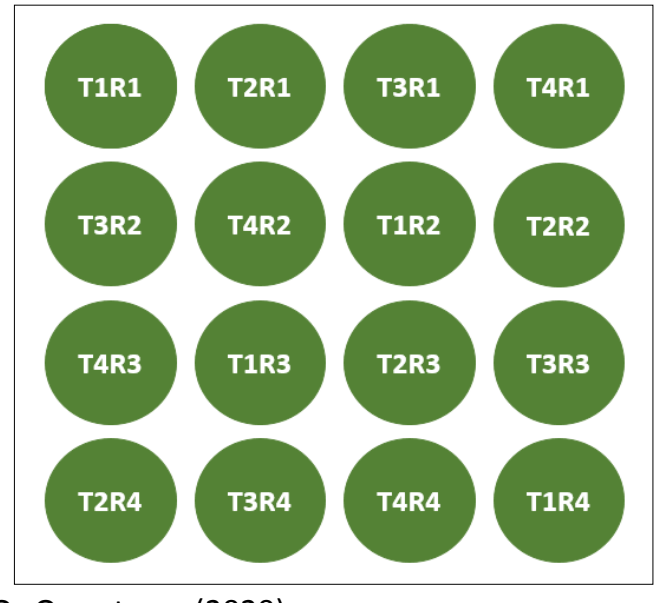

Fonte: Os Os autores (2020).

Os tratamentos foram caracterizados da seguinte forma:

- Tratamento 1 (T1) = Solo testemunha + Girassol;

- Tratamento 2 (T2) = Solo testemunha + Feijão de porco;

- Tratamento $3(\mathrm{~T} 3)$ = Solo lixão + Girassol;

- Tratamento $4(\mathrm{~T} 4)$ = Solo lixão + Feijão de porco.

Nas parcelas experimentais dos Tratamentos 1 e 3 foram semeadas, em cada 
parcela, duas sementes de girassol (Helianthus annuus), e, nas parcelas do Tratamento 2 e 4, foram semeadas duas sementes de feijão de porco (Canavalia ensiformis), em cada parcela. Os tratamentos permaneceram 45 dias em área experimental, sendo irrigados periodicamente através de irrigação existente na casa de vegetação.

\subsection{Preparo das amostras e análise de} fertilidade do solo

O restante do volume de solo foi acondicionado em bandejas de alumínio e em seguida submetido a secagem em estufa, a 100 oC de temperatura por um período de 24h. Após a secagem, as amostras foram destorroadas no almofariz, e peneiradas em peneira número 16, padronizada pela NBR NM ISO 3310 (ABNT, 2010).

Figura 4. Destorroamento do solo no almofariz.

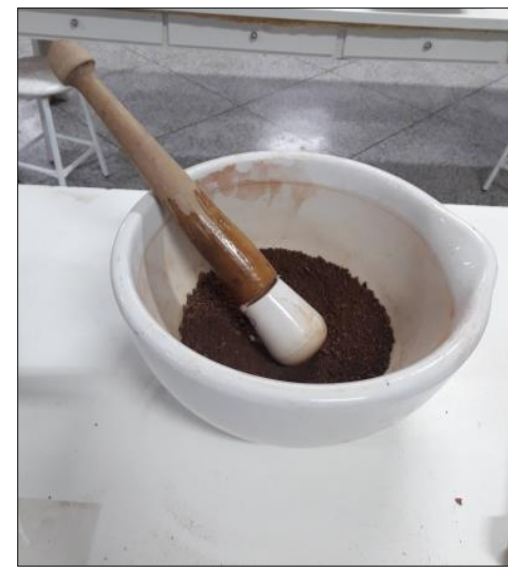

Fonte: Os autores (2020).

Figura 5. Peneiramento do solo em peneira № 16.

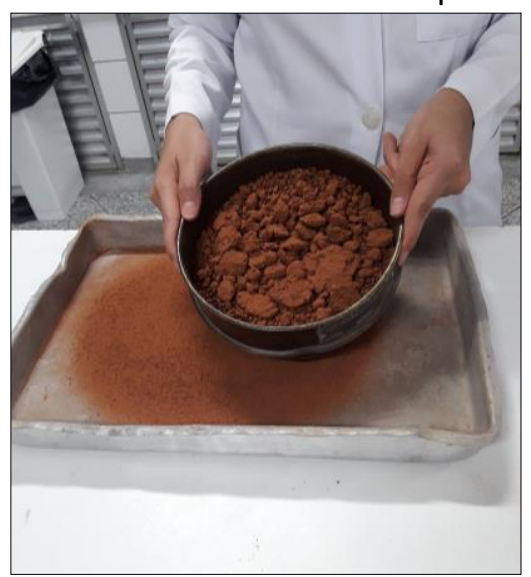

Fonte: Os autores (2020).

Em seguida, as amostras foram pesadas em balança digital semi-analítica (Figura 6) e acondicionadas em sacos plásticos transparente devidamente identificados (Figura 7).

Figura 6. Pesagem das amostras de solo.

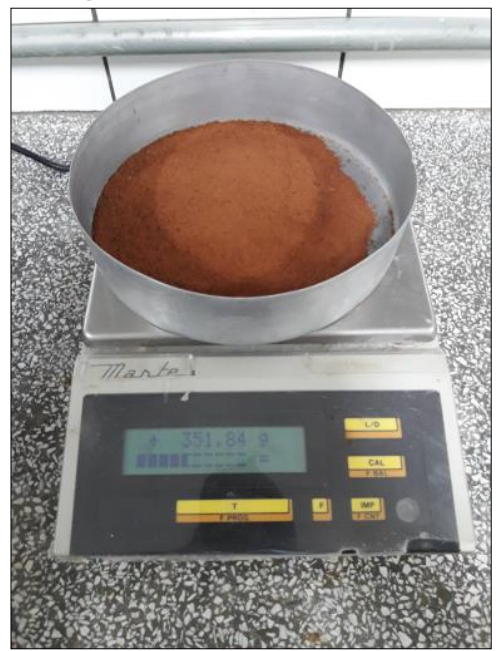

Fonte: Os Os autores (2020).

Figura 7. Amostras acondicionadas em sacos plásticos identificados.

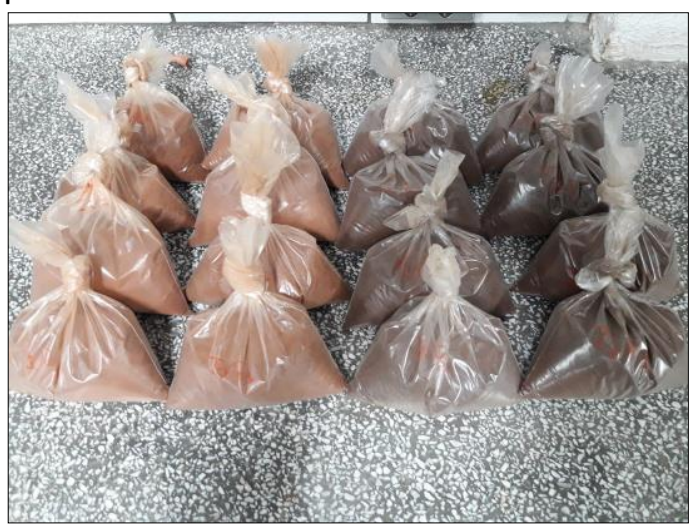

Fonte: Os autores (2020).

Para a análise de fertilidade do solo, as amostras foram encaminhadas ao Laboratório de Análise de Solos e Tecido Vegetal da UNOESTE, onde foram analisados, a partir da metodologia descrita por Raij et al. (2001), os seguintes parâmetros: $\mathrm{pH}, \mathrm{M} . \mathrm{O}$., $\mathrm{P}, \mathrm{K}, \mathrm{Ca}, \mathrm{Mg}, \mathrm{H}+\mathrm{Al}$.

\subsection{Análise das espécies vegetais}

A colheita das plantas foi realizada no 45응 dia de experimento. Com o auxílio de uma tesoura, a parte aérea foi cortada rente ao solo, e em seguida as raízes foram retiradas. Foram avaliados, conforme descrito por Malavolta et al. (1997), os seguintes parâmetros:

- Comprimento da parte aérea;

- Massa fresca e seca da raiz e da parte aérea;

Para a determinação da massa fresca da raiz e da parte aérea, as plantas foram 
armazenadas em sacos de papel kraft devidamente identificados, e em seguida foram pesadas em uma balança digital semi-analítica com precisão de duas casas decimais.

Figura 8. Balança digital semi-analítica.

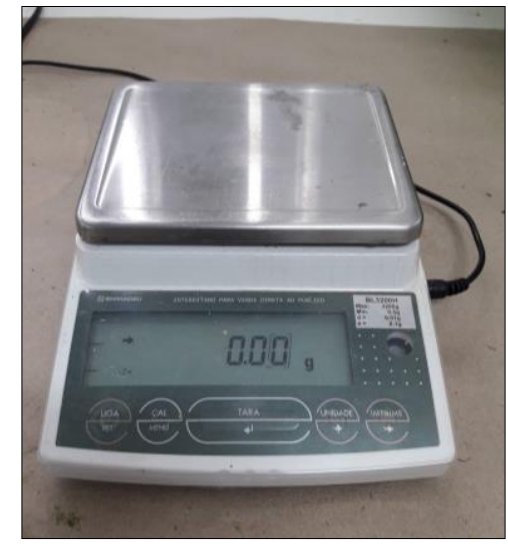

Fonte: Os autores (2020).

Após a pesagem, as plantas foram lavadas com detergente neutro e água corrente, seguida com água deionizada. Na sequência, as plantas foram submetidas a uma pré-secagem em exposição à bancada durante 16 horas. Em seguida, foram acondicionadas em sacos de papel kraft e conduzidas a secagem em estufa com circulação forçada de ar, a $65^{\circ} \mathrm{C}$ por 16 horas.

Figura 9. Lavagem das plantas

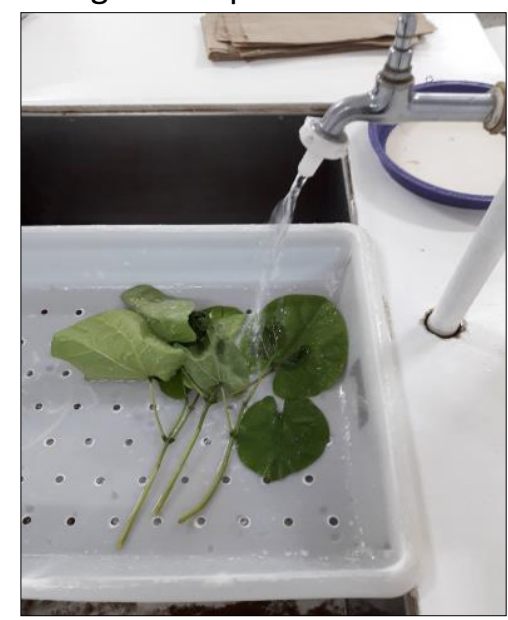

Fonte: Os autores (2020).
Figura 10. Pré-secagem em bancada.

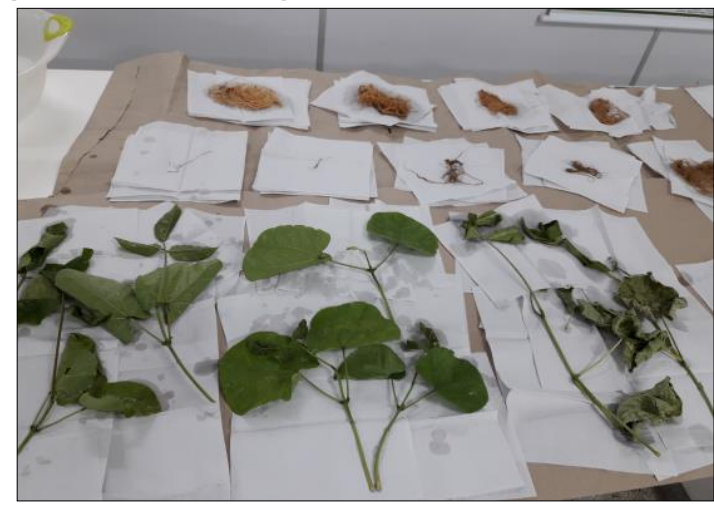

Fonte: Os Autores (2020).

Após esta etapa, para a obtenção da biomassa da matéria seca produzida, as amostras foram pesadas em balança digital semi-analítica com precisão de duas casas decimais, todos os valores foram anotados.

Figura 11. Pesagem da massa seca em balança digital.

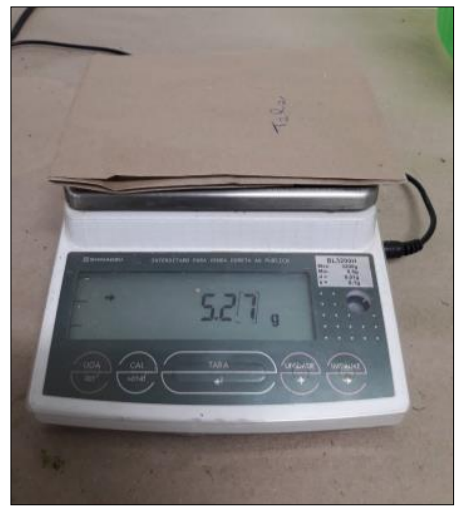

Fonte: Os autores (2020).

\subsection{Análise estatística dos dados}

Os resultados foram submetidos à análise de variância e ao teste de comparação de médias Tukey ao nível de $5 \%$ de probabilidade, através da utilização do Programa de Análises Estatísticas "Sisvar", versão 5.6.

\section{RESULTADOS E DISCUSSÃO}

\subsection{Análise de fertilidade do solo}

Os resultados da análise de fertilidade química ( $\mathrm{pH}, \mathrm{MO} \mathrm{P,} \mathrm{K,} \mathrm{Ca,} \mathrm{Mg,} \mathrm{H}+\mathrm{Al}$ ) do solo para os quatro tratamentos (T) estudados, estão descritos na Tabela 1. 
Tabela 1. Resultado do Teste de médias Tukey para a fertilidade do solo.

\begin{tabular}{|c|c|c|c|c|c|c|c|}
\hline$T$ & $\underset{(\mathrm{CaCl}}{\mathrm{pH}}$ & $\begin{array}{c}\text { M.O. } \\
\left.\text { (g.dm }{ }^{-3}\right)\end{array}$ & $\begin{array}{c}P \\
\left(\mathrm{mg} \mathrm{dm}^{-3}\right)\end{array}$ & $\mathrm{H}+\mathrm{Al}$ & $\begin{array}{c}\mathrm{K} \\
\text { (mmolc. }\end{array}$ & $\begin{array}{c}\mathrm{Ca} \\
\left.\mathrm{m}^{-3}\right)\end{array}$ & Mg \\
\hline 1 & $6,15 a b$ & $9,23 \mathrm{~b}$ & $3,35 b$ & ns & 1,78ab & $14,08 \mathrm{~b}$ & $3,8 b$ \\
\hline 2 & $5,75 b$ & $9,3 b$ & $2,95 b$ & ns & $1,08 \mathrm{~b}$ & $12,8 b$ & $3,48 b$ \\
\hline 3 & $7,00 a$ & $26,1 a$ & $106,07 a$ & ns & $3,7 a$ & $104,6 a$ & $14,6 a$ \\
\hline 4 & $7,05 a$ & $23,48 a$ & $79,85 a$ & ns & $2,33 a b$ & $90,55 a$ & $14,8 \mathrm{a}$ \\
\hline
\end{tabular}

A partir dos resultados apresentados, pode-se observar que o solo da área do lixão (T3 e T4) apresentou resultados superiores para todos os parâmetros em relação ao solo testemunha (T1 e T2), exceto para a acidez potencial, que não apresentou diferença estatística significativa entre os tratamentos.

Os valores de $\mathrm{pH}$ apresentaram diferença significativa entre o solo de lixão e o testemunha, sendo observado um maior valor no solo de lixão. Os resultados corroboram com Costa et al. (2017), que também observou o pH mais alto em área onde houve disposição de resíduos sólidos, permitindo constatar que a disposição de resíduos no solo pode provocar aumento do $\mathrm{pH}$.

Segundo Costa et al. (2017) os valores ideais de $\mathrm{pH}$ para receber a grande maioria das plantas deve se apresentar entre 5,8 a 7,5, o que foi verificado no solo de lixão estudado. Desta forma, considera-se que o $\mathrm{pH}$ não é um fator limitante para o desenvolvimento de plantas nesta área.

O valor médio do teor de matéria orgânica (M.O) do solo testemunha e do lixão foi de 9 e $25 \mathrm{~g} . \mathrm{dm}^{-3}$, respectivamente. A grande diferença observada no teor de M.O., indica a influência dos resíduos sólidos nesse parâmetro de qualidade do solo.

O teor de M.O. observado no solo do lixão desativado em estudo, foi superior ao obtido por Medeiros et al. (2008), em Engenheiro Coelho - SP, o qual atingiu um valor médio de 6 g.dm-3. Em contrapartida, os valores observados encontram-se abaixo dos valores obtidos por Medeiros et al. (2008), em Vargem Grande do Sul, onde se atingiu um teor de M.O. de $30 \mathrm{~g} . \mathrm{dm}^{-3}$ . Por fim, os resultados foram bem próximos aos obtidos por Beli et al. (2005), que ao avaliar o teor de M.O. em aterro não controlado, obteve 24 g.dm-3 de M.O.

Quanto aos macronutrientes, os resultados obtidos indicam significativa influência dos resíduos sólidos sobre a disponibilidade de nutrientes no solo. Os teores de fósforo, magnésio, cálcio e potássio, foram consideravelmente maiores no solo proveniente do lixão.

De acordo com Horta; Torrent (2010), o fósforo disponível no solo natural é baixo, porém, a grande degradação dos resíduos sólidos em lixões, provoca a fertilização, aumentando a quantidade de fósforo disponível nessas localidades, conforme observado no presente estudo.

O acúmulo de nutrientes como potássio, fósforo, magnésio e matéria orgânica no solo é característica da deposição de resíduos domiciliares, visto que esses elementos estão presentes em restos alimentares, plantas, entre outros resíduos orgânicos, já o cálcio, é oriundo principalmente de resíduos de construção civil (RODRIGUES; CAVINATTO, 2003).

\subsection{Produção de biomassa e comprimento das espécies vegetais}

A avaliação dos quatro tratamentos ( $\mathrm{T} 1$, T2, T3 e T4) em relação ao comprimento da parte aérea (CPA), à massa fresca da parte aérea (MFPA), massa fresca da raiz (MFR), massa seca da parte aérea (MSPA) e massa seca da raiz (MSR), mostrou diferenças significativas dos tratamentos entre si, não sendo observadas diferen ças entre as repetições, conforme apresentado na Tabela 2.

Tabela 2. Análise de variância (teste F).

\begin{tabular}{llllll}
\hline \multicolumn{1}{c}{ FV } & MFPA & MSPA & CPA & MFR & MSR \\
\hline Tratamento & $23,65^{* *}$ & $81,59^{* *}$ & $8,15^{*}$ & $25,76^{* *}$ & $39,04^{* *}$ \\
Repetição & $0,49^{n s}$ & $2,74^{\text {ns }}$ & $2,28^{\text {ns }}$ & $0,31^{\text {ns }}$ & $0,05^{\text {ns }}$ \\
*** $^{*}$ : significativo a 1 e 5\% de probabilidade; ns: não significativo. \\
Fonte: Os autores (2020).
\end{tabular}

Figura 12. Dados de massa fresca da parte aérea

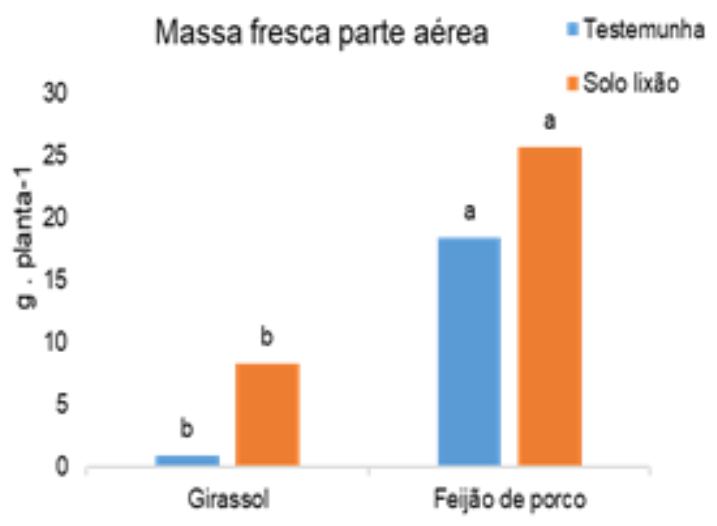

Fonte: Os autores (2020). 
Figura 13. Dados de massa seca da parte aérea

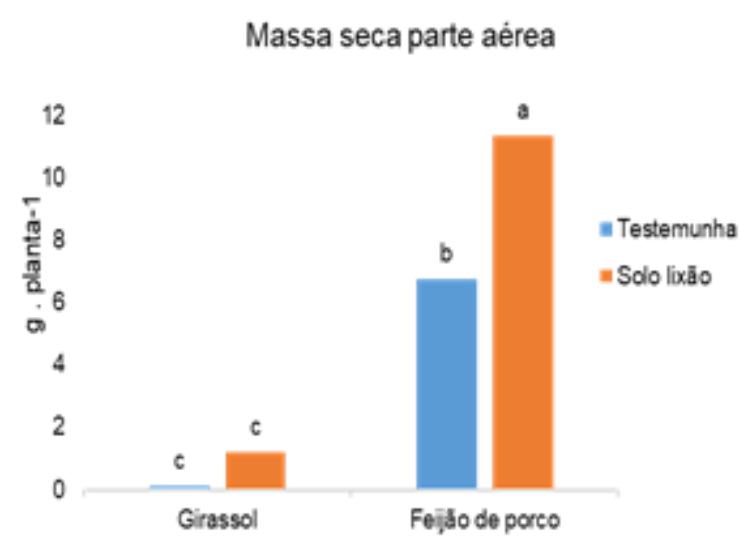

Fonte: Autores (2020)

Figura 14. Dados de massa fresca da raiz

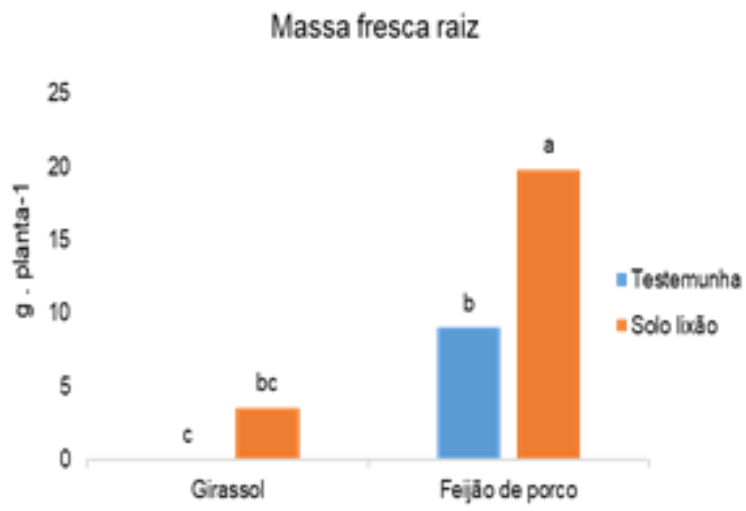

Fonte: Os autores (2020).

Figura 15. Dados de massa seca da raiz

Massa seca raiz

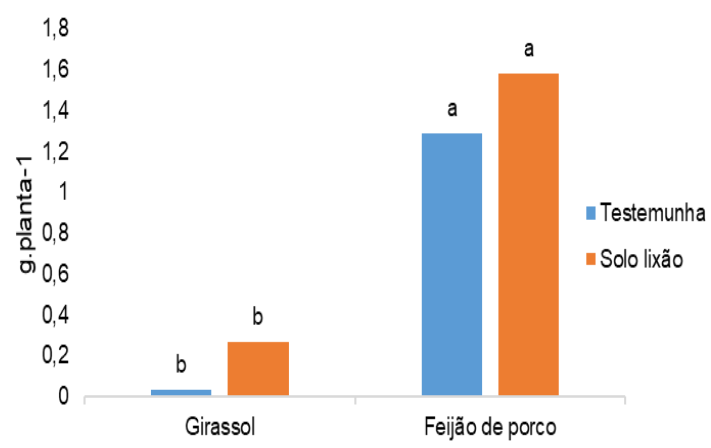

Fonte: Os autores (2020).

Analisando os dados de biomassa fresca e seca produzida pelas espécies vegetais, observase que o tratamento 4 , seguido do tratamento 2 , diferenciaram-se estatisticamente dos demais tratamentos, tanto na avaliação da parte aérea quanto da raiz.
Considerando que, nesses tratamentos a espécie utilizada foi o feijão de porco, os resultados obtidos corroboram com Almeida (2018), que ao avaliar o potencial fitoextrator das espécies de feijão de porco, manjericão, milho e girassol, constatou que o feijão de porco apresentou maior fitomassa seca em relação as demais espécies. A menor produção de matéria seca de parte aérea pelo girassol, também foi observada pelo autor.

Ao estudar cinco espécies herbáceas (feijão de porco, grama batatais, mamona, pinhão manso e vetiver), Assunção (2012) constatou, assim como no presente estudo, maior produção de biomassa do feijão de porco.

Nascimento et al. (2006), destacam que a extração de elementos do solo pela planta está diretamente relacionada com a quantidade de matéria seca que ela produz, sendo a produção de biomassa associada à absorção e transporte do contaminante, fatores importantes na escolha da espécie a ser utilizada no processo de fitorremediação.

Portanto, a avaliação da produção de biomassa faz-se importante quando se quer avaliar o potencial fitoextrator de uma determinada espécie. Para Garbisu e Alkorta (2001), a planta ideal para fitoextração deve possuir, entre outras características, taxa de crescimento rápido, alta produção de biomassa e grande acúmulo de metal na parte aérea.

Além de ter produzido maior biomassa quando comparado ao girassol, o feijão de porco também se destacou por apresentar maior comprimento da parte aérea, o que pode ser justificado pela rápida taxa de crescimento dessa espécie.

Figura 16. Dados do comprimento da parte aérea Comprimento parte aérea

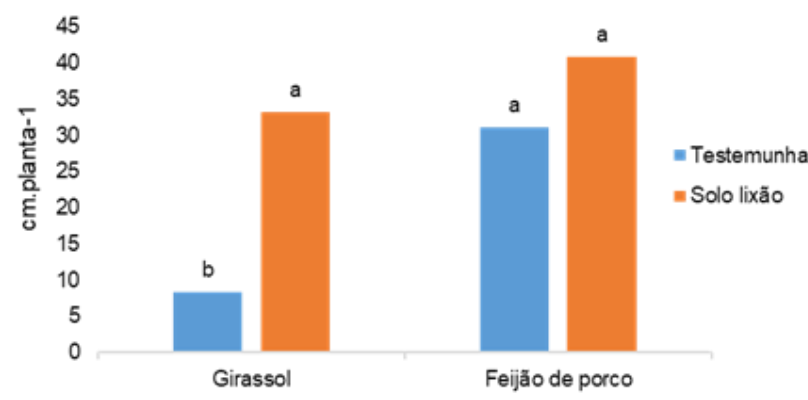

Fonte: Os autores (2020).

Savani (2016), ao avaliar o potencial fitorremediador do feijão de porco, observou um 
rápido crescimento da espécie nas semanas iniciais de seu experimento.

Considerando que 0 período de realização do experimento ( 45 dias) foi inferior ao ciclo vegetativo completo de ambas as espécies, pode-se constatar que a velocidade do crescimento inicial dessas espécies teve influência nos valores de comprimento.

A acelerada taxa de crescimento inicial do feijão de porco, contribuiu para que a espécie apresentasse maior comprimento. Considerando o crescimento inicial mais lento do girassol, há a possibilidade dessa espécie alcançar os mesmos valores de comprimento do feijão de porco, em um período experimental maior que 45 dias.

\section{CONSIDERAÇÕES FINAIS}

A degradação dos solos ocasionada pela disposição inadequada de resíduos sólidos em lixões pode perdurar mesmo após o seu encerramento. Os resíduos sólidos exercem grande influência na disponibilidade de nutrientes do solo, acarretando maior acúmulo de macronutrientes como o fósforo, magnésio, cálcio e potássio, além de elevar os teores de matéria orgânica, devido a contínua decomposição desses resíduos.

Considerando a importância da remediação de passivos ambientais e a possibilidade do uso de plantas nesse processo, a espécie de feijão de porco apresentou desenvolvimento satisfatório ao ser cultivada em solo de área de lixão. Destacando-se pela maior produção de biomassa, quando comparada ao girassol, que teve um crescimento inicial mais lento e baixa produção de biomassa.

Diante do exposto, o melhor desenvolvimento e produção de biomassa do feijão de porco, indicam a possibilidade de uso dessa espécie na fitorremediação de solo de passivo ambiental oriundo da disposição inadequada de resíduos sólidos urbanos.

Contudo, vale ressaltar que para a escolha da planta ideal para a aplicação da técnica de fitorremediação devem ser avaliados, além da produção de biomassa, a redução do teor dos elementos no solo e consequente acúmulo dos mesmos no tecido vegetal das espécies.

\section{REFERÊNCIAS}

ALMEIDA, R. de. Fitoextração de metais pesados em solo contaminado por escória de minério de chumbo, no município de Santo Amaro - BA. Faculdade Maria Milza - FAMAM, 2018.

ASSOCIAÇÃO BRASILEIRA DE NORMAS TÉCNICAS. Norma Brasileira ISO 3310: Peneiras de ensaio Requisitos técnicos e verificação - Parte "I Peneiras de ensaio com tela de tecido metálico (ISO 3310-1:2000, IDT), 2010.

ASSOCIAÇÃO BRASILEIRA DE EMPRESAS DE LIMPEZA PÚBLICA. Panorama dos Resíduos Sólidos no Brasil 2018/2019. Disponível em: https://abrelpe.org.br/panorama/. Acesso em: 15 ago. 2020.

ASSUNÇÃO, S. J. R. Seleção de plantas para fitorremediação de chumbo, cádmio e zinco de uma área contaminada na Bacia do Rio Subaé. 2012.Dissertação (Mestrado) - Universidade Federal do Recôncavo da Bahia, Centro de Ciências Agrárias, Ambientais e Biológicas, 2012.

BARBOSA, A. de M. Caracterização climática de Presidente Prudente - SP. BOLETIM AGROMETEOROLÓGICO, Presidente Prudente, n. 01, jul., 2020. Disponível em: http://sites.unoeste.br/clima/wpcontent/uploads/2020/07/Boletim-01Caracteriza\%C3\%A7\%C3\%A3o-Clim\%C3\%A1ticade-Presidente-Prudente-2.pdf. Acesso em: 15 nov. 2020.

BELI, E. et al. Recuperação de área degradada pelo lixão areia branca de Espírito Santo do Pinhal - SP. Engenharia Ambiental, Espírito Santos do Pinhal-SP, v. 2, n. 1, p. 135-148, 2005.

BRASIL. Congresso Nacional. Lei no 12.305 de 02 de agosto de 2010. Institui a Política Nacional de Resíduos Sólidos. Diário Oficial da União, Brasília, DF, 02 ago. 2010. Disponível em: http://www.planalto.gov.br/ccivil 03/ ato20072010/2010/lei//12305.htm. Acesso em: 24 ago. 2020.

COUTINHO, H. D.; BARBOSA, A. R. Fitorremediação: Considerações Gerais e Características de Utilização. A. R, p. 15, 2007.

COSTA, B. M. B. et al. Analise e caracterização química do solo em locais de acomodação de resíduos hospitalares no município de Cuité-PB. Revista Gestão \& Sustentabilidade Ambiental, 
Florianópolis, v. 6, n. 1, p. 83 - 100, 2017. https://doi.org/10.19177/rgsa.v6e1201783-100

GARBISU, C.; ALKORTA I. Phytoextraction: a costeffective plantbased technology for the removal of metals from the environment,Bioresource Technology, v. 77, n. 3, p. 229-236 2001. https://doi.org/10.1016/S0960-8524(00)00108-5

HORTA, M. C.; TORRENT, J. Dinâmica do Fósforo no Solo, Perspectiva Agronómica e Ambiental. 1. ed. Portugal: IPCB, 2010. 101p.

LAMEGO, F. P.; VIDAL, R. A. Fitorremediação: plantas como agentes de despoluição?. Revista de Ecotoxicologia e Meio Ambiente, Curitiba, v. 17, p. 9-18, jan./dez. 2007. https://doi.org/10.5380/pes.v17i0.10662

MALAVOLTA, E.; VITTI, G.C.; OLIVEIRA S.A. Avaliação do estado nutricional das plantas princípios e aplicações. 2. ed. Piracicaba [s.n.], 1997.

MARINHO, A. P. F. et al. Contaminação do solo por zinco, cobre e bário em área de disposição irregular de resíduos sólidos urbanos no semiárido potiguar. São Paulo: ABES Associação Brasileira de Engenharia Sanitária e Ambiental, 2019.

MEDEIROS, G. A. et al. Diagnóstico da qualidade da água e do solo no lixão de Engenheiro Coelho, no Estado de São Paulo. Engenharia Ambiental: Pesquisa e Tecnologia , Brasília, DF, 5.2, 2008. Disponível em: http://ferramentas.unipinhal.edu.br/engenhariaa mbiental/viewarticle. $p h p$ ?id=135. Acesso em: 29 nov. 2020.

NASCIMENTO, C. W. A. et al. Comparison of natural organic acids and synthetic chelates at enhancing phytoextraction of metals from a multimetal contaminated soil. Environmental Pollution, v. 140, p. 114-123, 2006. https://doi.org/10.1016/i.envpol.2005.06.017

RAIJ, B. V. Análise química para avaliação da fertilidade de solos tropicais. Instituto Agronômico. Campinas, SP, 2001.

RODRIGUES, F .L.; CAVINATTO, V. M. Lixo de onde vem, pra onde vai? São Paulo: Moderna, 2003. 95 p.
SAVANI, F. R. Avaliação de feijão de porco (canavalia ensiformis) como fitorremediador de $\mathrm{Pb}, \mathrm{Cu}$ E Zn EM SOLOS. Universidade Federal do $A B C$ - UFABC Programa De Pós-Graduação Em Ciência E Tecnologia Ambiental, Santo André- SP 2016. 